09,04

\title{
Спектральные и структурные характеристики молибдатов $\left(\mathrm{Lu}_{1-x} \mathrm{Eu}_{x}\right)_{2}\left(\mathrm{MoO}_{4}\right)_{3}$
}

\author{
() С.З. Шмурак, В.В. Кедров, А.П. Киселев, Т.Н. Фурсова, И.И. Зверькова, С.С. Хасанов \\ Институт физики твердого тела РАН, \\ Черноголовка, Россия \\ E-mail: shmurak@issp.ac.ru.
}

(Поступила в Редакцию 28 ноября 2018 г.

В окончательной редакции 28 ноября 2018 г.

Принята к публикации 29 ноября 2018 г.)

\begin{abstract}
Проведены исследования структуры, спектров фотолюминесценции и ИК-поглощения твердых растворов $\left(\mathrm{Lu}_{1-x} \mathrm{Eu}_{x}\right)_{2}\left(\mathrm{MoO}_{4}\right)_{3}$ в широком диапазоне концентраций европия $(0 \leq x \leq 1)$. Установлено соответствие между структурой и спектральными характеристиками этих соединений. С ростом концентрации европия происходит последовательная смена трех типов кристаллических фаз. Впервые исследованы спектры фотолюминесценции и ИК-поглощения моноклинной фазы с пространственной группой $P 2_{1} / a$. Показано, что максимум свечения при резонансном возбуждении ионов $\mathrm{Eu}^{3+}$ наблюдается в образцах с орторомбической структурой $P b a 2$ при $x \sim 0.8$. При возбуждении в полосе с переносом заряда максимальную интенсивность люминесценции имеют образцы, находящиеся в моноклинной фазе $P 2_{1} / a$ при $x \sim 0.2$.
\end{abstract}

Работа авполнена в рамках госзадания ИФТТ РАН.

DOI: 10.21883/FTT.2019.04.47425.324

\section{1. Введение}

В ряде работ установлено однозначное соответствие между структурным состоянием и спектральными характеристиками целого ряда соединений. Например, в ортоборатах $\mathrm{LuBO}_{3}$ : Ce [1-3] в спектре свечения кальцитной модификации максимумы фотолюминесценции наблюдаются при $\lambda_{\max }=365$ и $400 \mathrm{~nm}$, а для ватеритной модификации - при $\lambda_{\max }=395$ и $425 \mathrm{~nm}$. Исследование спектров люминесценции бората лютеция, легированного европием, при УФ возбуждении показало, что для кальцитной модификации $\mathrm{LuBO}_{3}: \mathrm{Eu}$ характерно оранжевое свечение, а для ватеритной - красное свечение [4-7].

Однозначное соответствие между структурными состояниями молибдатов европия и легированного европием гадолиния $\left(\mathrm{Gd}_{1-x} \mathrm{Eu}_{x}\right)_{2}\left(\mathrm{MoO}_{4}\right)_{3}$ и их спектральными характеристиками установлено в работах [8-11]. Каждой структурной модификации соответствует характерный только для нее спектр люминесценции.

Таким образом, изменяя структурное состояние описанных выше соединений, можно направленно управлять их спектральными характеристиками. Это крайне важно, например, при тонкой спектральной подстройке свечения светодиодных источников „белого“ света (white lightemitting diodes, WLED), которые находят все более широкое распространение, вытесняя традиционные источники света.

Представляется целесообразным проведение исследований связи между структурой и спектральными характеристиками фотолюминесценции и ИК-поглощения твердых растворов молибдатов лютеция и европия $\left(\mathrm{Lu}_{1-x} \mathrm{Eu}_{x}\right)_{2}\left(\mathrm{MoO}_{4}\right)_{3}$ в широком диапазоне концентраций $\mathrm{Lu}^{3+}$ и $\mathrm{Eu}^{3+}$.
Молибдат европия $\mathrm{Eu}_{2}\left(\mathrm{MoO}_{4}\right)_{3}$ имеет несколько устойчивых структурных модификаций $[12,13]$. При низких температурах стабильной является моноклинная $\alpha$-фаза (пр. гр. № 15, $C 2 / c)$. При $T_{t}=881^{\circ} \alpha$-фаза переходит в тетрагональную $\beta$-фазу (пр. гр. № $113, P \overline{4} 2{ }_{1} m$ ). Следует отметить, что удельный объем $\beta$-фазы на $25 \%$ больше, чем $\alpha$-фазы, поэтому при синтезе $\mathrm{Eu}_{2}\left(\mathrm{MoO}_{4}\right)_{3}$ при $T>T_{t}$ и последующем охлаждении, даже при малых скоростях, если не использовать специальные режимы охлаждения, переход из $\beta$ - в $\alpha$-фазу подавляется из-за большой разности удельных объемов этих структурных модификаций. Поэтому молибдат европия остается в метастабильной $\beta$-фазе вплоть до температуры $180^{\circ} \mathrm{C}$, при которой происходит подгрупповой переход в орторомбическую $\beta^{\prime}$-фазу Pba 2 (пр. гр. № 32), сопровождаемый слабыми структурными изменениями [13].

Структурные исследования соединения $\mathrm{Lu}_{2}\left(\mathrm{MoO}_{4}\right)_{3}$ проводились в небольшом количестве работ [12-14]. Согласно данным этих работ, молибдат лютеция имеет одну структурную модификацию - орторомбическую $\alpha$-фазу (пр.гр. №60, Pbcn). Однако, как показано в данной работе, при использованной нами методике синтеза $\mathrm{Lu}_{2}\left(\mathrm{MoO}_{4}\right)_{3}$ кристаллизуется в моноклинной структуре и относится к пространственной группе $P 2_{1} / a$ (пр. гр. № 14).

В настоящей работе проведены исследования изменения структуры твердого раствора $\left(\mathrm{Lu}_{1-x} \mathrm{Eu}_{x}\right)_{2}\left(\mathrm{MoO}_{4}\right)_{3}$ в зависимости от соотношения между концентрациями $\mathrm{Lu}^{3+}$ и $\mathrm{Eu}^{3+}$. Установлено соответствие между структурой и спектральными характеристиками этого соединения. Определены составы, имеющие максимальную интенсивность свечения ионов $\mathrm{Eu}^{3+}$ в $\left(\mathrm{Lu}_{1-x} \mathrm{Eu}_{x}\right)_{2}\left(\mathrm{MoO}_{4}\right)_{3}$. 


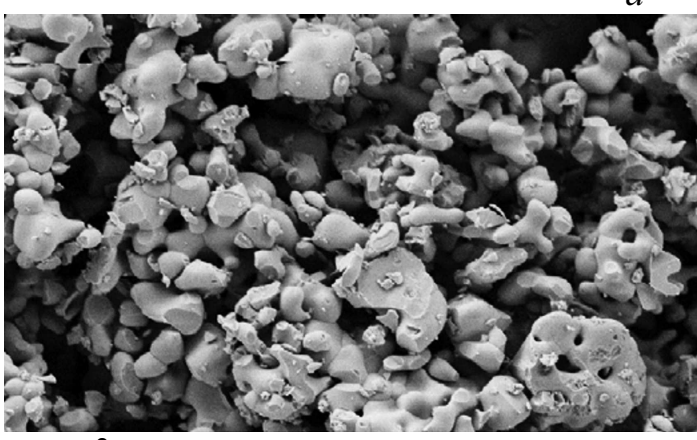

$-3 \mu \mathrm{m}$

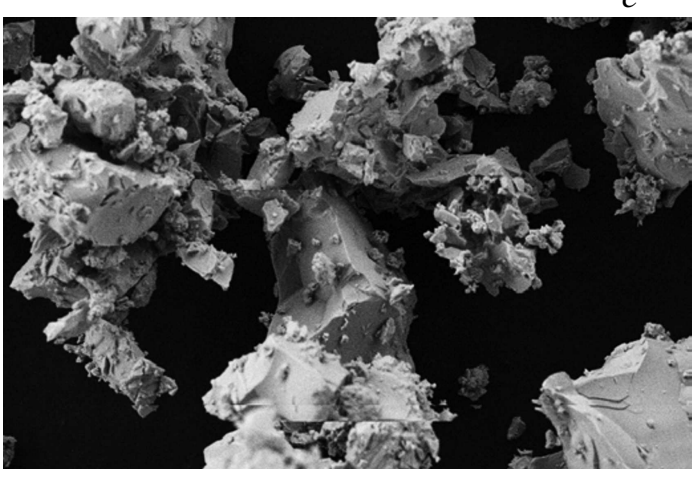

$-3 \mu \mathrm{m}$

$e$

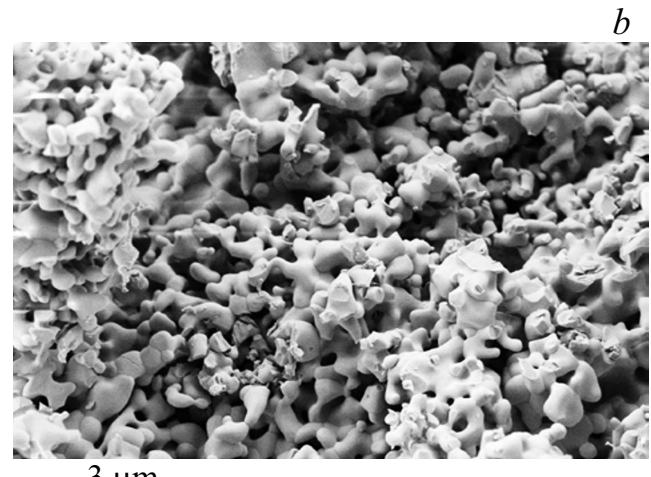

$-3 \mu \mathrm{m}$

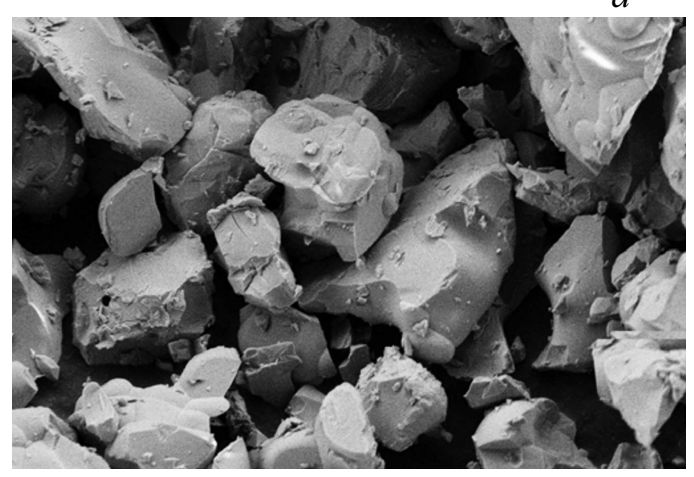

$-3 \mu \mathrm{m}$ b

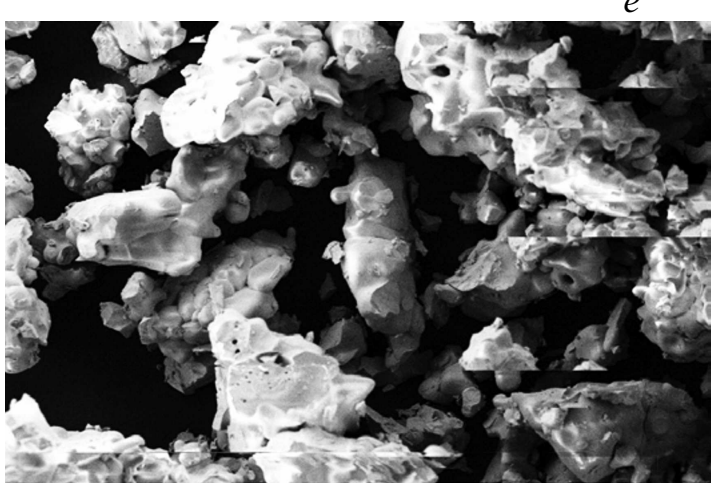

$-10 \mu \mathrm{m}$

Рис. 1. Морфология молибдатов $\left(\mathrm{Lu}_{1-x} \mathrm{Eu}_{x}\right)_{2}\left(\mathrm{MoO}_{4}\right)_{3} . a-\mathrm{Lu}_{2}\left(\mathrm{MoO}_{4}\right)_{3} ; b-\left(\mathrm{Lu}_{0.8} \mathrm{Eu}_{0.2}\right)_{2}\left(\mathrm{MoO}_{4}\right)_{3} ; c-\left(\mathrm{Lu}_{0.5} \mathrm{Eu}_{0.5}\right)_{2}\left(\mathrm{MoO}_{4}\right)_{3} ;$ $d-\left(\mathrm{Lu}_{0.2} \mathrm{Eu}_{0.8}\right)_{2}\left(\mathrm{MoO}_{4}\right)_{3} ; e-\mathrm{Eu}_{2}\left(\mathrm{MoO}_{4}\right)_{3}$.

\section{2. Методика эксперимента}

В качестве исходных соединений для синтеза молибдатов лютеция и европия были использованы парамолибдат аммония $\left(\mathrm{NH}_{4}\right)_{6} \mathrm{Mo}_{7} \mathrm{O}_{24} \cdot 4 \mathrm{H}_{2} \mathrm{O}$, оксиды $\mathrm{Lu}_{2} \mathrm{O}_{3}$, $\mathrm{Eu}_{2} \mathrm{O}_{3}$, азотная кислота и водный аммиак. Все использованные химические вещества соответствовали квалификации „ЧДА“. Ионы $\mathrm{Lu}^{3+}$ и $\mathrm{Eu}^{3+}$ вводились в реакцию в виде водных растворов нитратных солей, которые получали растворением исходных оксидов редких земель в азотной кислоте. Синтез мелкодисперсных порошков молибдатов состава $\left(\mathrm{Lu}_{1-x} \mathrm{Eu}_{x}\right)_{2}\left(\mathrm{MoO}_{4}\right)_{3}$ проводился следующим образом. К водному раствору парамолибдата аммония $\left(\mathrm{NH}_{4}\right)_{6} \mathrm{Mo}_{7} \mathrm{O}_{24} \cdot 4 \mathrm{H}_{2} \mathrm{O}$ добавляли стехиометрические количества нитратов лютеция и европия. При этом суммарная концентрация ионов $\mathrm{Lu}^{3+}$ и $\mathrm{Eu}^{3+}$ в объеме 30-40 ml составляла величину $(1.0-1.3) 10^{-4} \mathrm{~mol} / \mathrm{l}$. Далее в реакционную массу при интенсивном перемешивании добавляли водный аммиак $(15 \%)$ до значения $\mathrm{PH}=7-8$. Образовавшийся гель осторожно высушивали до образования твердого продукта, который далее отжигали при $450^{\circ} \mathrm{C}$ в течение одного часа для удаления остаточной влаги и разложения нитратных солей. Полученный продукт тщательно перетирали в агатовой ступке, переносили в корундовый тигель и подвергали высокотемпературному отжигу при $970^{\circ} \mathrm{C}$ в течение $2 \mathrm{~h}$.

Рентгенодифракционные исследования образцов полученных молибдатов проводились с использованием дифрактометра Bruker Phaser-2 (излучение $\mathrm{Co} K_{\alpha}$, 
$\lambda=1.7903 \AA)$. Фазовый анализ образцов и расчет параметров решетки проводился с использованием программ Match и PowderCell 2.4.

ИК-спектры поглощения образцов измерялись на фурье-спектрометре VERTEX 80v в спектральном диапазоне $50-5000 \mathrm{~cm}^{-1} \mathrm{c}$ разрешением $2 \mathrm{~cm}^{-1}$. Для измерений образцы молибдатов дополнительно перетирались в агатовой ступке, а затем тонким слоем наносились на кристаллическую шлифованную подложку $\mathrm{KBr}$ или полиэтиленовую подложку.

Морфология образцов изучалась с использованием рентгеновского микроанализатора Supra 50VP с приставкой для EDS INCA (Oxford).

Спектры фотолюминесценции и спектры возбуждения люминесценции изучались на установке, состоящей из источника света - лампы ДКСШ-150, двух монохроматоров МДР-4 и МДР-6 (спектральный диапазон $200-1000 \mathrm{~nm}$, дисперсия $1.3 \mathrm{~nm} / \mathrm{mm})$. Регистрация свечения осуществлялась фотоумножителем ФЭУ-106 (область спектральной чувствительности $200-800 \mathrm{~nm}$ ) и усилительной системой. Монохроматор МДР-4 использовался для изучения спектров возбуждения люминесценции образцов, монохроматор МДР-6 применялся для изучения спектров люминесценции. Структурные и спектральные исследования образцов проводились на воздухе при комнатной температуре.

\section{3. Морфология образцов}

На рис. 1 представлена морфология образцов молибдата лютеция с разным содержанием европия. С увеличением содержания европия в образцах $\left(\mathrm{Lu}_{1-x} \mathrm{Eu}_{x}\right)_{2}\left(\mathrm{MoO}_{4}\right)_{3}$ от $x=0.01$ до $x=0.4$ происходит увеличение количества округлых частиц (рис. $1, a, b$ ) при размере частиц $3-5 \mu \mathrm{m}$. Дальнейшее увеличение количества европия приводит к увеличению размера частиц до $10-20 \mu \mathrm{m}$, при этом возрастает количество ограненных частиц, достигая максимума при 80 at.\% (рис. $1, c, d, e$ ).

\section{4. Рентгеноструктурные исследования}

Дифрактограммы порошковых образцов исследуемых соединений приведены на рис. 2. Образец состава $\mathrm{Eu}_{2}\left(\mathrm{MoO}_{4}\right)_{3}$ практически однофазный со структурой, аналогичной $\mathrm{Gd}_{2}\left(\mathrm{MoO}_{4}\right)_{3}$, PDF 70-1397, пространственная группа $P b a 2$ (пр. гр. № 32), $Z=4$, экспериментальные значения параметров решетки: $a=10.409 \AA$, $b=10.445 \AA, c=10.727 \AA, V=1163.2 \AA^{3}$.

Образец состава $\mathrm{Lu}_{2}\left(\mathrm{MoO}_{4}\right)_{3}$ однофазный со структурой, аналогичной $\mathrm{Fe}_{2}\left(\mathrm{MoO}_{4}\right)_{3}$, пространственная группа $P 2_{1} / a$ (пр. гр. № 14), $Z=8$, экспериментальные значения параметров решетки: $a=16.338 \AA, b=10.129 \AA$, $c=19.272 \AA, \beta=125.47^{\circ}, V=2597.2 \AA^{3}$.
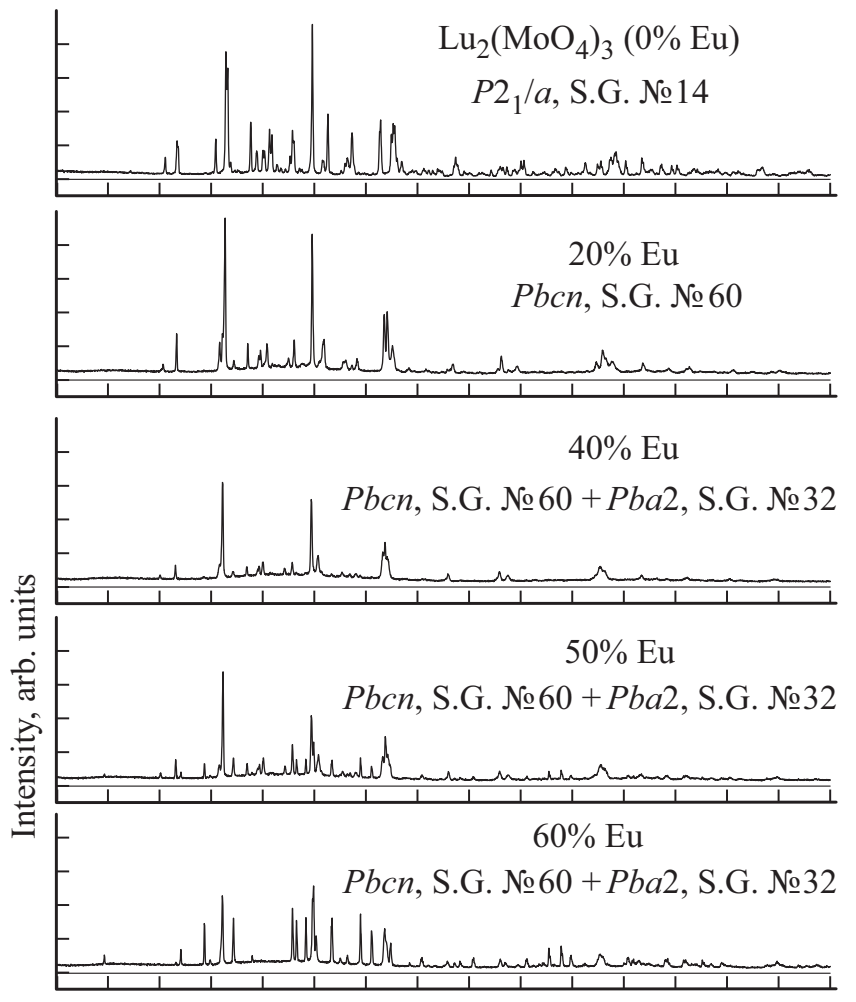

$80 \% \mathrm{Eu}$

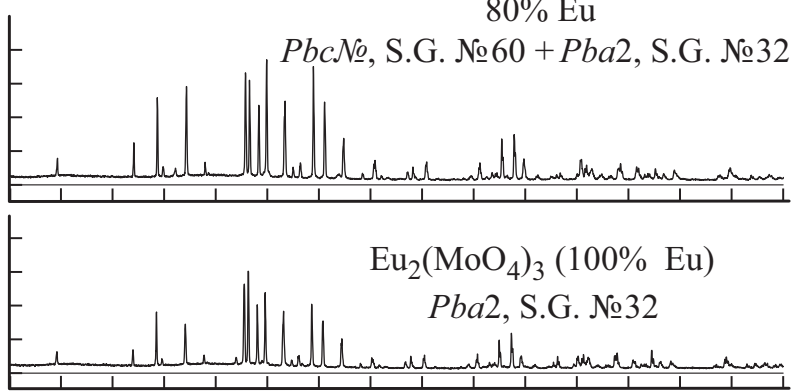

$\begin{array}{llllllllllllllll}5 & 10 & 15 & 20 & 25 & 30 & 35 & 40 & 45 & 50 & 55 & 60 & 65 & 70 & 75 & 80\end{array}$ $2 \theta$, deg, $\operatorname{Co} K_{\alpha}$

Pис. 2. Дифрактограммы молибдатов $\left(\mathrm{Lu}_{1-x} \mathrm{Eu}_{x}\right)_{2}\left(\mathrm{MoO}_{4}\right)_{3}$.

Синтез из шихты, содержащей оба редкоземельных элемента (Eu и $\mathrm{Lu})$, приводит к образованию кристаллических структур твердых растворов $\left(\mathrm{Lu}_{1-x} \mathrm{Eu}_{x}\right)_{2}\left(\mathrm{MoO}_{4}\right)_{3}$. В этом ряду замещение атомов $\mathrm{Lu}$ атомами Еu приводит к переходу из вышеназванной моноклинной фазы, $P 2_{1} / a$, в известную орторомбическую фазу, $P b c n$ (пр.гр. № 60), $Z=4$, структурный тип $\mathrm{Sc}_{2}\left(\mathrm{WO}_{4}\right)_{3}$. Надо отметить, что эти фазы родственны, и моноклинная фаза является результатом незначительного искажения более высокосимметричной орторомбической фазы в результате подгруппового фазового перехода. При дальнейшем изложении их можно объединить в один структурный тип 1 , чтобы подчеркнуть их принципиальное отличие от структуры $\mathrm{Eu}_{2}\left(\mathrm{MoO}_{4}\right)_{3}$ структурного типа 2. Отличие заключается в первую очередь в том, что тип 2 имеет более плотную структуру (на $12 \%)$. В структурном плане релевантное к свойствам 


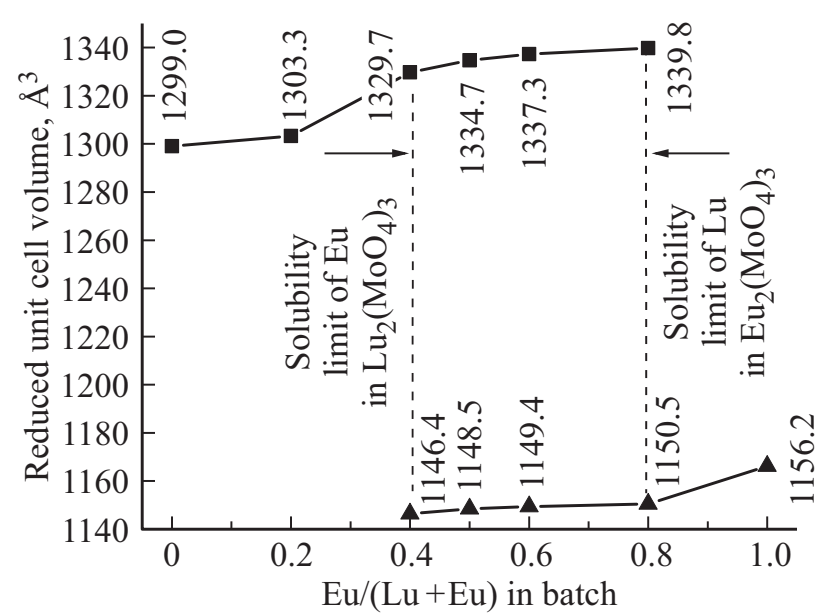

Рис. 3. Объемы элементарных ячеек фаз, приведенные к $Z=4, \AA^{3}$.

отличие является более принципиальным, а именно, окружение фотоактивных ионов $\mathrm{Eu}^{+3}$ в структурном типе 1 является шестикратным, октаэдрическим, и семикратным - в структурном типе 2 .

Замещение атомов $\mathrm{Lu}$ атомами $\mathrm{Eu}$ сопровождается увеличением объема элементарной ячейки кристаллической структуры ввиду большего ионного радиуса последнего (ионные радиусы $\mathrm{Eu}^{3+}$ и $\mathrm{Lu}^{3+}$ существенно различны: $0.950 \AA$ для $\mathrm{Eu}^{3+}$ и $0.848 \AA$ для $\left.\mathrm{Lu}^{3+}[15]\right)$ (рис. 3). В заданных условиях синтеза при составе $x=0.4$ наступает насыщение растворимости: объем перестает заметно расти, появляется вторая фаза на основе структурного типа $\mathrm{Eu}_{2}\left(\mathrm{MoO}_{4}\right)_{3}$ - структурного типа 2 . Поэтому фаза со структурным типом 1 имеет почти постоянный состав, приблизительно $\left(\mathrm{Lu}_{0.6} \mathrm{Eu}_{0.4}\right)_{2}\left(\mathrm{MoO}_{4}\right)_{3}$, то есть не меняется при дальнейшем увеличении содержания Eu в шихте. Вторая фаза со структурным типом 2 также является твердым раствором, но уже состава $\left(\mathrm{Lu}_{0.2} \mathrm{Eu}_{0.8}\right)_{2}\left(\mathrm{MoO}_{4}\right)_{3}$ приблизительно, не меняясь до состава шихты $\mathrm{Lu}: \mathrm{Eu}=0.2: 0.8$. В диапазоне содержания европия от 40 at.\% до 80 at.\% составы фаз твердых растворов не меняются, а изменяется относительное их количество, при составе 80 at.\% фаза структурного типа 1 исчезает. При дальнейшем увеличении содержания $\mathrm{Eu}$, то есть при дальнейшем уменьшении содержания $\mathrm{Lu}$ в структуре типа 2, объем ячейки структуры твердого раствора $\left(\mathrm{Lu}_{1-x} \mathrm{Eu}_{x}\right)_{2}\left(\mathrm{MoO}_{4}\right)_{3}$ начинает увеличиваться (рис. 3).

Следует отметить, что в молибдате $\left(\mathrm{Lu}_{1-x} \mathrm{Eu}_{x}\right)_{2}\left(\mathrm{MoO}_{4}\right)_{3} \quad$ при $\quad x \leq 0.4 \quad$ наряду со структурным типом 1 (моноклинной при $x \leq 0.2$, а затем и орторомбической при $0.2 \leq x \leq 0.4$ фазами) наблюдается небольшое количество соединения $\left(\mathrm{Lu}_{0.2} \mathrm{Eu}_{0.8}\right)_{2}\left(\mathrm{MoO}_{4}\right)_{3}$ (структурный тип 2). Однако из-за малой доли этой структуры, еe количественное определение затруднительно.

\section{5. Результаты ИК-спектроскопии}

На рис. 4 показаны спектры ИК-поглощения $\mathrm{Lu}_{2}\left(\mathrm{MoO}_{4}\right)_{3}$ (спектр 1), $\mathrm{Eu}_{2}\left(\mathrm{MoO}_{4}\right)_{3}$ (спектр 7) и спектры смешанных составов $\left(\mathrm{Lu}_{1-x} \mathrm{Eu}_{x}\right)_{2}\left(\mathrm{MoO}_{4}\right)_{3}$ (спектры 2-6). В структурах молибдатов лютеция и европия присутствуют два типа координационных полиэдров. В моноклинной структуре $\mathrm{Lu}_{2}\left(\mathrm{MoO}_{4}\right)_{3}\left(P 2_{1} / a\right)$ - октаэдр $\mathrm{LuO}_{6}$ и тетраэдр $\mathrm{MoO}_{4}$ [16]. В орторомбической структуре $\mathrm{Eu}_{2}\left(\mathrm{MoO}_{4}\right)_{3}(\mathrm{Pba2})$ - тригональная призма с шапкой $\mathrm{EuO}_{7}$ и тетраэдр $\mathrm{MoO}_{4}$ [17]. Элементарные ячейки этих структур содержат $136(Z=8)$ и $68(Z=4)$ атомов для $\mathrm{Lu}_{2}\left(\mathrm{MoO}_{4}\right)_{3}$ и $\mathrm{Eu}_{2}\left(\mathrm{MoO}_{4}\right)_{3}$ соответственно, поэтому теоретически в колебательном спектре этих кристаллов может наблюдаться 405 и 201 оптических мод соответственно. При анализе спектров оптических фононов подобных структур анионную группу $\mathrm{MoO}_{4}^{2-}$ рассматривают как единую молекулу. Предполагается, что силы связи Мо-О внутри этой группы значительно превосходят ее силы связи с катионной подрешеткой. Это позволяет разделить колебания на внутренние ко-

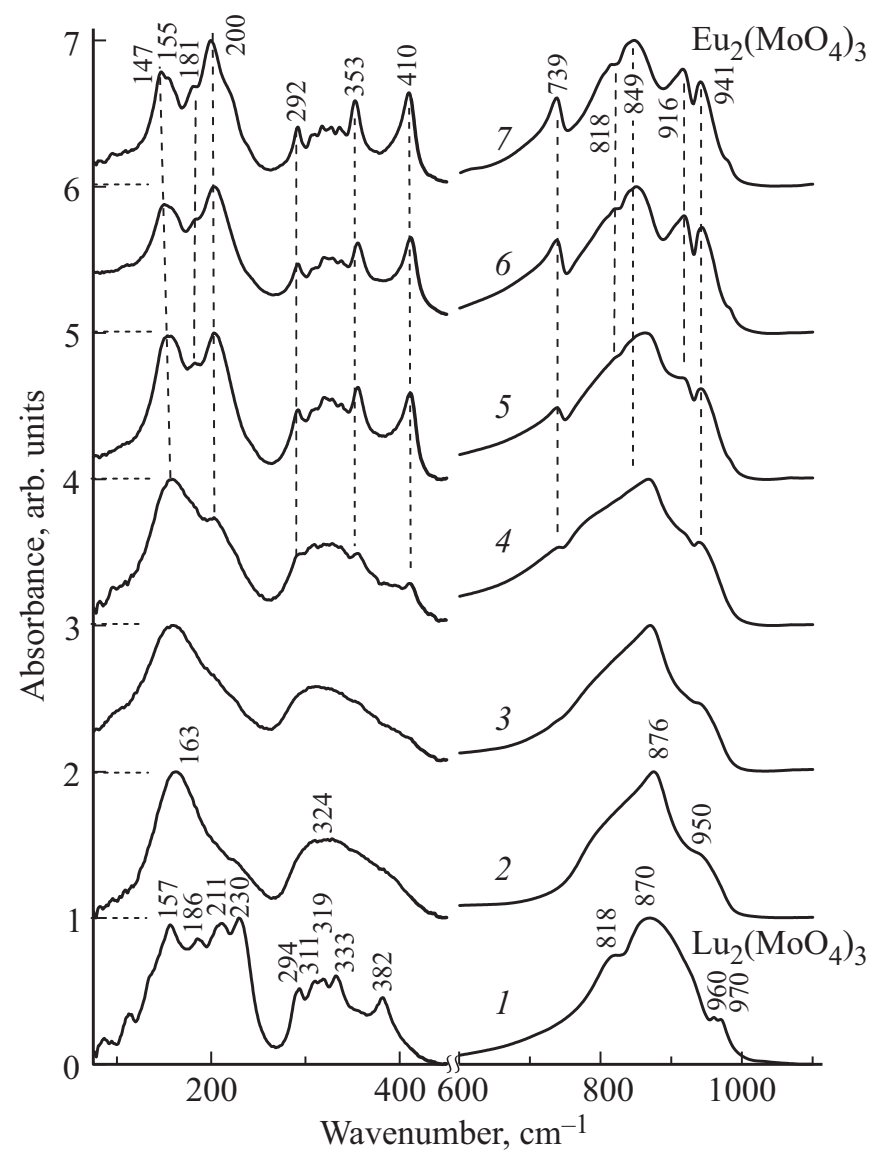

Рис. 4. ИК-спектры поглощения молибдатов $\left(\mathrm{Lu}_{1-x} \mathrm{Eu}_{x}\right)_{2}\left(\mathrm{MoO}_{4}\right)_{3} . \quad 1-\mathrm{Lu}_{2}\left(\mathrm{MoO}_{4}\right)_{3} ; \quad 2$ $\left(\mathrm{Lu}_{0.8} \mathrm{Eu}_{0.2}\right)_{2}\left(\mathrm{MoO}_{4}\right)_{3} ; \quad 3-\left(\mathrm{Lu}_{0.6} \mathrm{Eu}_{0.4}\right)_{2}\left(\mathrm{MoO}_{4}\right)_{3} ; 4-$ $\left(\mathrm{Lu}_{0.5} \mathrm{Eu}_{0.5}\right)_{2}\left(\mathrm{MoO}_{4}\right)_{3} ; \quad 5-\left(\mathrm{Lu}_{0.4} \mathrm{Eu}_{0.6}\right)_{2}\left(\mathrm{MoO}_{4}\right)_{3} ; 6-$ $\left(\mathrm{Lu}_{0.2} \mathrm{Eu}_{0.8}\right)_{2}\left(\mathrm{MoO}_{4}\right)_{3} ; 7-\mathrm{Eu}_{2}\left(\mathrm{MoO}_{4}\right)_{3}$. Горизонтальный штрих-пунктир - ось абсцисс к спектрам 2-7. 
лебания ионов $\mathrm{MoO}_{4}^{2-}$ и внешние колебания, когда молекула движется как жесткое целое. Внешние колебания включают трансляционные движения редкоземельных катионов и анионов $\mathrm{MoO}_{4}^{2-}$, при которых смещаются их центры масс, а также либрационные, при которых изменяется ориентация анионов $\mathrm{MoO}_{4}^{2-}$.

Исследования ИК-спектров оптических фононов молибдатов изоморфных соединений [18-21] позволяют связать линии поглощения в диапазонах $600-1000$ и $280-420 \mathrm{~cm}^{-1}$ в ИК-спектрах моноклинного $\mathrm{Lu}_{2}\left(\mathrm{MoO}_{4}\right)_{3}$ (рис. 4, спектр 1) и орторомбического $\mathrm{Eu}_{2}\left(\mathrm{MoO}_{4}\right)_{3}$ (рис. 4, спектр 7) с внутренними валентными и деформационными колебаниями связи Мо-О аниона $\mathrm{MoO}_{4}^{2-}$ соответственно. Поглощение в низкочастотной области с $v<280 \mathrm{~cm}^{-1}$ обусловлено внешними колебаниями [22].

Следует отметить, что ИК-спектры составов $\left(\mathrm{Lu}_{1-x} \mathrm{Eu}_{x}\right)_{2}\left(\mathrm{MoO}_{4}\right)_{3} \quad$ c $x=0.05-0.15$ совпадают со спектром $\mathrm{Lu}_{2}\left(\mathrm{MoO}_{4}\right)_{3}$, имеющего моноклинную структуру.

При переходе от соединения $\mathrm{Lu}_{2}\left(\mathrm{MoO}_{4}\right)_{3}$ с моноклинной структурой к соединению $\left(\mathrm{Lu}_{0.8} \mathrm{Eu}_{0.2}\right)_{2}\left(\mathrm{MoO}_{4}\right)_{3}$ (рис. 4, спектры 1 и 2 соответственно) группа линий поглощения с частотами 157, 186, 211 и $230 \mathrm{~cm}^{-1}$, обусловленных внешними колебаниями, трансформируется в широкую полосу поглощения с максимумом $\sim 163 \mathrm{~cm}^{-1}$. Аналогичные изменения происходят в области внутренних колебаний иона $\mathrm{MoO}_{4}^{2-}$. Линии поглощения 294, 311, 319, 333 и $382 \mathrm{~cm}^{-1}$, обусловленные деформационными колебаниями, трансформируются в широкую полосу поглощения с максимумом $324 \mathrm{~cm}^{-1}$. Вместо набора линий валентных колебаний - 818, 870,960 и $970 \mathrm{~cm}^{-1}$ возникает асимметричная полоса с максимумом $876 \mathrm{~cm}^{-1}$ и плечом $\sim 950 \mathrm{~cm}^{-1}$. В спектре соединения $\left(\mathrm{Lu}_{0.6} \mathrm{Eu}_{0.4}\right)_{2}\left(\mathrm{MoO}_{4}\right)_{3}$ (спектр 3) наблюдается небольшое увеличение полуширины полосы внешних колебаний $\sim 163 \mathrm{~cm}^{-1}$.

Как показал рентгенофазовый анализ, соединения $\left(\mathrm{Lu}_{0.8} \mathrm{Eu}_{0.2}\right)_{2}\left(\mathrm{MoO}_{4}\right)_{3}$ и $\left(\mathrm{Lu}_{0.6} \mathrm{Eu}_{0.4}\right)_{2}\left(\mathrm{MoO}_{4}\right)_{3}$ имеют орторомбическую структуру с пространственной группой $P b c n$ и являются твердыми растворами на основе молибдата лютеция. Эта структура относится к тому же структурному типу, что и моноклинная структура с пространственной группой $P 2_{1} / a$ соединения $\mathrm{Lu}_{2}\left(\mathrm{MoO}_{4}\right)_{3}-$ структурный тип 1 .

Следует заметить, что в спектрах соединений $\left(\mathrm{Lu}_{0.8} \mathrm{Eu}_{0.2}\right)_{2}\left(\mathrm{MoO}_{4}\right)_{3}$ и $\left(\mathrm{Lu}_{0.6} \mathrm{Eu}_{0.4}\right)_{2}\left(\mathrm{MoO}_{4}\right)_{3}$ с орторомбической структурой Pbcn (рис. 4) наблюдается меньшее количество линий, чем в спектре $\mathrm{Lu}_{2}\left(\mathrm{MoO}_{4}\right)_{3}$ [21, рис. 1] с такой же структурой. Вероятно, это связано с уширением линий фононных мод, обусловленным локальными искажениями кристаллической решетки в окрестности атома редкоземельного иона из-за различия ионных радиусов $\mathrm{Eu}$ и $\mathrm{Lu}$.

ИК спектр поглощения соединения $\mathrm{Eu}_{2}\left(\mathrm{MoO}_{4}\right)_{3}$, имеющего орторомбическую структуру с пространственной группой Pba2 (структурный тип 2), содержит в области внешних колебаний ряд линий - 147, 155, 181 и $200 \mathrm{~cm}^{-1}$ (рис. 4, спектр 7), которые наблюдались в спектре отражения кристалла $\mathrm{Eu}_{2}\left(\mathrm{MoO}_{4}\right)_{3}$ [23]. Две самые интенсивные линии в этой области $147 \mathrm{~cm}^{-1}$ и $200 \mathrm{~cm}^{-1}$ являются трансляционным колебанием редкоземельного иона и либрационным колебанием иона $\mathrm{MoO}_{4}^{2-}$ соответственно [22]. В диапазоне внутренних колебаний самые интенсивные линии деформационных колебаний $-292,353$ и $410 \mathrm{~cm}^{-1}$, валентных - 739, $818,849,916$ и $941 \mathrm{~cm}^{-1}$.

В спектре соединения $\left(\mathrm{Lu}_{0.5} \mathrm{Eu}_{0.5}\right)_{2}\left(\mathrm{MoO}_{4}\right)_{3}$ (рис. 4, спектр 4) практически все эти линии наблюдаются на фоне профиля спектра орторомбической фазы со структурным типом 1 (спектры 2 и 3). Таким образом, спектр состава $\left(\mathrm{Lu}_{0.5} \mathrm{Eu}_{0.5}\right)_{2}\left(\mathrm{MoO}_{4}\right)_{3}$ представляет собой суперпозицию спектров орторомбических фаз с разными структурными типами - 1 и 2, что согласуется с данными рентгенофазового анализа.

При дальнейшем увеличении содержания европия в $\left(\mathrm{Lu}_{0.5} \mathrm{Eu}_{0.5}\right)_{2}\left(\mathrm{MoO}_{4}\right)_{3}$ в спектре $\left(\mathrm{Lu}_{0.4} \mathrm{Eu}_{0.6}\right)_{2}\left(\mathrm{MoO}_{4}\right)_{3}$ (рис. 4, спектр 5) интенсивность ранее наблюдаемых линий увеличивается и появляются линии 181,818 и $916 \mathrm{~cm}^{-1}$, которые не наблюдались в ИК-спектре $\left(\mathrm{Lu}_{0.5} \mathrm{Eu}_{0.5}\right)_{2}\left(\mathrm{MoO}_{4}\right)_{3}$. Спектр состава $\left(\mathrm{Lu}_{0.2} \mathrm{Eu}_{0.8}\right)_{2}\left(\mathrm{MoO}_{4}\right)_{3}$ (рис. 4, спектр 6) включает тот же набор линий поглощения, что и $\mathrm{Eu}_{2}\left(\mathrm{MoO}_{4}\right)_{3}$ (рис. 4, спектр 7). Описанная трансформация наблюдаемых спектров 1-7 коррелирует с данными рентгенофазового анализа.

Переход из моноклинной структуры в орторомбическую наблюдался ранее для изоструктурного соединения $\mathrm{Fe}_{2}\left(\mathrm{MoO}_{4}\right)_{3}$ при интеркалировании его ионами $\mathrm{Li}^{+}$[24]. В этом случае атомы щелочного металла, занимая пустоты в моноклинной решетке „хозяина“ $-\mathrm{Fe}_{2}\left(\mathrm{MoO}_{4}\right)_{3}$, вызывают деформацию решетки и инициируют фазовый переход. В нашем случае подобный фазовый переход инициируется замещением ионов $\mathrm{Lu}$ атомами $\mathrm{Eu}$, имеющими больший ионный радиус, что приводит к трансформации моноклинной структуры в орторомбическую структуру (пр.гр. Pbcn).

\section{6. Спектры люминесценции и спектры возбуждения люминесценции}

\section{1. Спектры люминесценции}

Фотолюминесценция $\mathrm{Eu}^{3+} \quad$ в соединениях $\left(\mathrm{Lu}_{1-x} \mathrm{Eu}_{x}\right)_{2}\left(\mathrm{MoO}_{4}\right)_{3}$ наблюдается в диапазоне длин волн 570-720 nm. Спектр люминесценции содержит ряд линий, обусловленных электронными переходами ${ }^{5} \mathrm{D}_{0} \rightarrow{ }^{7} \mathrm{Fi} \quad(i=0-4) \quad[25] \quad$ (рис. 5). Как видно из pис. 5, на котором приведены спектры люминесценции этих молибдатов при $x=0.05,0.4,0.5,0.6$ и 1 , наиболее интенсивные полосы свечения наблюдаются в диапазоне длин волн 605-630 nm, (электронный переход 
$E, \mathrm{eV}$

$2.152 .102 .052 .001 .95 \quad 1.90 \quad 1.85 \quad 1.80 \quad 1.75$

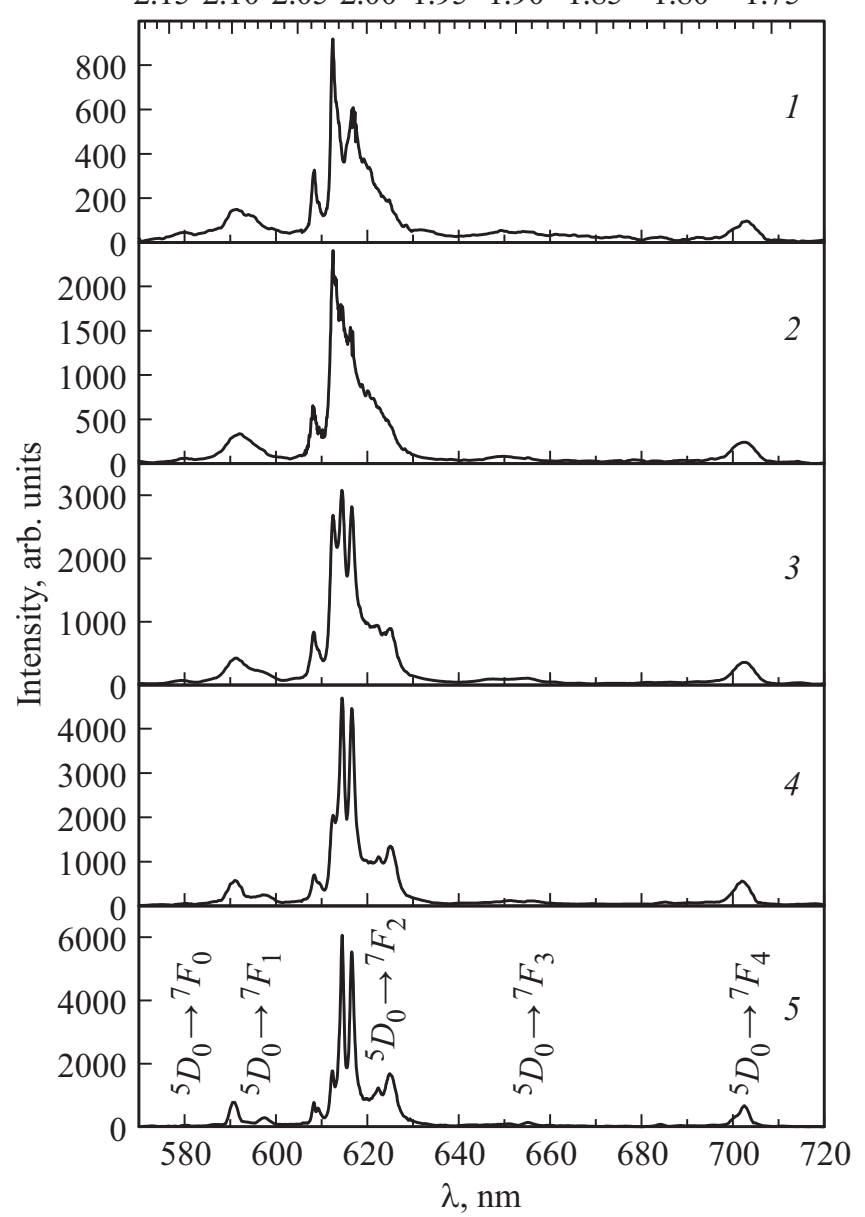

Рис. 5. Спектры люминесценции молибдатов $\left(\mathrm{Lu}_{1-x} \mathrm{Eu}_{x}\right)_{2}\left(\mathrm{MoO}_{4}\right)_{3}$ при возбуждении светом с $\lambda_{\mathrm{ex}}=395 \mathrm{~nm}$. $1-\left(\mathrm{Lu}_{0.95} \mathrm{Eu}_{0.05}\right)_{2}\left(\mathrm{MoO}_{4}\right)_{3} ; 2-\left(\mathrm{Lu}_{0.6} \mathrm{Eu}_{0.4}\right)_{2}\left(\mathrm{MoO}_{4}\right)_{3}$; $3-\left(\mathrm{Lu}_{0.5} \mathrm{Eu}_{0.5}\right)_{2}\left(\mathrm{MoO}_{4}\right)_{3} ; 4-\left(\mathrm{Lu}_{0.4} \mathrm{Eu}_{0.6}\right)_{2}\left(\mathrm{MoO}_{4}\right)_{3} ; 5-$ $\mathrm{Eu}_{2}\left(\mathrm{MoO}_{4}\right)_{3}$.

$\left.{ }^{5} \mathrm{D}_{0} \rightarrow{ }^{7} \mathrm{~F}_{2}\right)$. При изменении количества ионов $\mathrm{Eu}^{3+}(x)$ именно в этом диапазоне длин волн наблюдаются существенные изменения спектральных характеристик люминесценции, которые мы будем обсуждать в дальнейшем. Следует отметить, что образец $\mathrm{Lu}_{2}\left(\mathrm{MoO}_{4}\right)_{3}$ в исследуемом диапазоне длин волн оптически неактивен, поэтому исследования спектральных характеристик соединений $\left(\mathrm{Lu}_{1-x} \mathrm{Eu}_{x}\right)_{2}\left(\mathrm{MoO}_{4}\right)_{3}$ производились при $x \geq 0.01$.

Спектры фотолюминесценции твердых растворов молибдатов $\left(\mathrm{Lu}_{1-x} \mathrm{Eu}_{x}\right)_{2}\left(\mathrm{MoO}_{4}\right)_{3}$ при изменении $x$ от 0.01 до 1 приведены на рис. 5 и 6. При изменении $x$ в интервале $0.01-0.15$ спектры фотолюминесценции практически не изменяются: в спектре люминесценции наблюдается три полосы с $\lambda_{\max } \sim 608.3, \sim 612.4$ и $\sim 616.6 \mathrm{~nm}$. Наиболее интенсивной является полоса с $\lambda_{\max } \sim 612.4 \mathrm{~nm}$. При увеличении $x$ от 0.01 до 0.15 ее интенсивность увеличивается в $\sim 8$ раз. Существенное изменение спектра люминесценции (СЛ) происходит при $x=0.2$. Наиболее интенсивными в СЛ становятся две полосы с $\lambda_{\max } \sim 608.3$ и $612.4 \mathrm{~nm}$. Их полуширины заметно уменьшаются от $\sim 1.25$ и $\sim 1.26$ до $\sim 0.85$ и $\sim 0.95 \mathrm{~nm}$ соответственно. Интенсивности остальных полос почти на порядок меньше наиболее интенсивной полосы $612.4 \mathrm{~nm}$ (рис. 5,6). Эти же полосы являются наиболее интенсивными при $x=0.4$, однако в СЛ этих образцов увеличивается интенсивность полос 614.4 и $616.6 \mathrm{~nm}$. Дальнейший рост интенсивности этих полос наблюдается при $x=0.45$, а при $x=0.5$ полосы 612.4 , 614.4 и $616.6 \mathrm{~nm}$ имеют примерно одинаковую интенсивность. При дальнейшем увеличении доли европия (при $x>0.5$ ) снова происходят значительные изменения спектра люминесценции: в СЛ наблюдается значительно

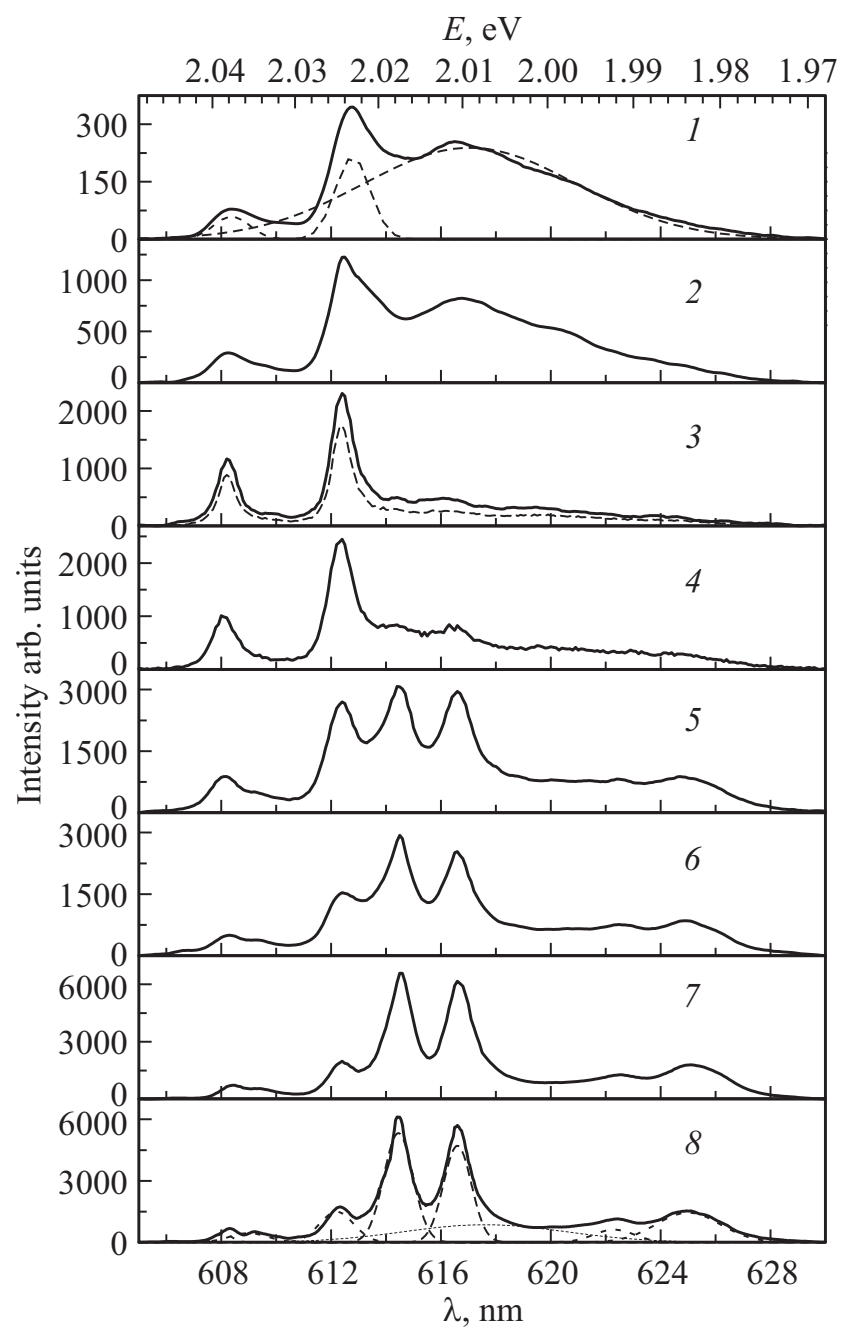

Рис. 6. Спектры люминесценции молибдатов $\left(\mathrm{Lu}_{1-x} \mathrm{Eu}_{x}\right)_{2}\left(\mathrm{MoO}_{4}\right)_{3}$ в диапазоне длин волн 605-630 nm. $1-\left(\mathrm{Lu}_{0.99} \mathrm{Eu}_{0.01}\right)_{2}\left(\mathrm{MoO}_{4}\right)_{3} ; 2-\left(\mathrm{Lu}_{0.9} \mathrm{Eu}_{0.1}\right)_{2}\left(\mathrm{MoO}_{4}\right)_{3}$; $3-\left(\mathrm{Lu}_{0.8} \mathrm{Eu}_{0.2}\right)_{2}\left(\mathrm{MoO}_{4}\right)_{3} ; 4-\left(\mathrm{Lu}_{0.6} \mathrm{Eu}_{0.4}\right)_{2}\left(\mathrm{MoO}_{4}\right)_{3} ; 5-$ $\left(\mathrm{Lu}_{0.5} \mathrm{Eu}_{0.5}\right)_{2}\left(\mathrm{MoO}_{4}\right)_{3} ; 6-\left(\mathrm{Lu}_{0.45} \mathrm{Eu}_{0.55}\right)_{2}\left(\mathrm{MoO}_{4}\right)_{3} ; 7-$ $\left(\mathrm{Lu}_{0.2} \mathrm{Eu}_{0.8}\right)_{2}\left(\mathrm{MoO}_{4}\right)_{3} ; 8-\mathrm{Eu}_{2}\left(\mathrm{MoO}_{4}\right)_{3}$. Спектр 3 (штриховая линия) получен при $\lambda_{\mathrm{ex}}=282 \mathrm{~nm}$; для всех других спектров люминесценции $\lambda_{\mathrm{ex}}=395 \mathrm{~nm}$. Штриховые линии на спектрах 1 и $8-$ разложение на гауссовы составляющие. 
большее число полос с $\lambda_{\max }=608.3,609.3,612.4,614.4$, $616.6,622.5$ и $624.8 \mathrm{~nm}$, при этом наибольшую интенсивность имеют полосы 614.4 и $616.6 \mathrm{~nm}$. Спектр люминесценции в дальнейшем не изменяется при увеличении концентрации $\mathrm{Eu}^{3+}$ вплоть до $100 \%(x=1)$. Он совпадает со спектром люминесценции орторомбической $\beta^{\prime}$-фазы $\mathrm{Eu}_{2}\left(\mathrm{MoO}_{4}\right)_{3}$ (пр.гр. Рba2) $[9,10]$. При $x>0.5$ интенсивность свечения увеличивается с повышением доли ионов $\mathrm{Eu}^{3+}$, достигая максимума (6575 отн.ед.) при $x=0.8$ для наиболее интенсивной полосы $614.4 \mathrm{~nm}$ (рис. 6).

Следует отметить, что спектры люминесценции образцов $\left(\mathrm{Lu}_{1-x} \mathrm{Eu}_{x}\right)_{2}\left(\mathrm{MoO}_{4}\right)_{3}$ во всем исследованном интервале значений при $0.01 \leq x \leq 1$ не зависят от длины волны возбуждающего света. При возбуждении образцов светом в коротковолновой области спектра (полосе с переносом заряда, ППЗ) с $\lambda_{\mathrm{ex}}=282-288 \mathrm{~nm}$ и в максимуме резонансного возбуждения $\mathrm{Eu}^{3+}$-ионов $\lambda_{\mathrm{ex}}=395 \mathrm{~nm}$ наблюдаются одни и те же спектры свечения. В качестве примера на рис. 6 приведены спектры люминесценции соединения $\left(\mathrm{Lu}_{0.8} \mathrm{Eu}_{0.2}\right)_{2}\left(\mathrm{MoO}_{4}\right)_{3}$ при $\lambda_{\mathrm{ex}}=282$ и $395 \mathrm{~nm}$.

При сопоставлении результатов спектральных исследований и рентгенофазового анализа молибдатов $\left(\mathrm{Lu}_{1-x} \mathrm{Eu}_{x}\right)_{2}\left(\mathrm{MoO}_{4}\right)_{3}$ наблюдается соответствие между структурным состоянием и спектральными характеристиками исследованных образцов (см. таблицу). Действительно, при $x<0.2$ твердый раствор $\left(\mathrm{Lu}_{1-x} \mathrm{Eu}_{x}\right)_{2}\left(\mathrm{MoO}_{4}\right)_{3}$ имеет моноклинную структуру (пр.гр. $\left.P 2_{1} / a\right)$. Соответствующий этой структуре спектр люминесценции содержит 3 полосы с $\lambda_{\max } \sim 608.3$, $\sim 612.4$ и $\sim 616.6 \mathrm{~nm}$. При $0.2<x<0.4$ структура $\left(\mathrm{Lu}_{1-x} \mathrm{Eu}_{x}\right)_{2}\left(\mathrm{MoO}_{4}\right)_{3}$ орторомбическая (пр.гр. Pbcn). В спектре люминесценции этого соединения наибольшую интенсивность имеют только две полосы с $\lambda_{\max } \sim 608.3$ и $612.4 \mathrm{~nm}$. Как отмечалось в разд. 4, моноклинная фаза (пр.гр. $P 21 / a$ ) представляет собой незначительно искаженную более высоко симметричную орторомбическую фазу (пр.гр. Pbcn). В обеих этих структурах оптически активный ион $\mathrm{Eu}^{3+}$ окружен 6 анионами кислорода. В моноклинной структуре для редкоземельного иона существуют 4 неэквивалентные позиции [16], в то время как в орторомбической фазе (пр.гр. Pbcn) для редкоземельного иона имеется только одна позиция [26]. Эти различия являются причиной уширения спектральных линий в моноклинной структуре и появления новой широкой полосы $\lambda_{\max } \sim 616.6 \mathrm{~nm}$.

Следует отметить, что при синтезе соединения $\left(\mathrm{Lu}_{1-x} \mathrm{Eu}_{x}\right)_{2}\left(\mathrm{MoO}_{4}\right)_{3}$ при $x \leq 0.4$, наряду с моноклинной и орторомбической фазой (пр.гр. Pbcn) образуется орторомбическая фаза $\left(\mathrm{Lu}_{0.2} \mathrm{Eu}_{0.8}\right)_{2}\left(\mathrm{MoO}_{4}\right)_{3}$ (пр. гр. Pba2), (рис. 3), однако ее количество составляет при $x=0.4$ всего $\sim 10 \%$ и поэтому она не вносит существенного вклада в спектральные характеристики исследуемых образцов (рис. 6, спектр 4).

Существенные изменения спектра люминесценции происходят при $x>0.5$. Соединение
$\left(\mathrm{Lu}_{1-x} \mathrm{Eu}_{x}\right)_{2}\left(\mathrm{MoO}_{4}\right)_{3}$ имеет также орторомбическую структуру (пр.гр. Pba2), в которой ион $\mathrm{Eu}^{3+}$ окружен не 6, а 7 анионами кислорода. В спектре люминесценции этого соединения, как отмечалось, наблюдается ряд новых полос, среди которых наибольшую интенсивность имеют полосы $\sim 614.4$ и $\sim 616.6 \mathrm{~nm}$. Особо следует выделить состав $\left(\mathrm{Lu}_{0.5} \mathrm{Eu}_{0.5}\right)_{2}\left(\mathrm{MoO}_{4}\right)_{3}, \quad$ спектр люминесценции которого является суперпозицией спектров орторомбических фаз $\left(\mathrm{Lu}_{1-x} \mathrm{Eu}_{x}\right)_{2}\left(\mathrm{MoO}_{4}\right)_{3}$ $(0.2<x<0.5) \quad$ (пр. гр. Рbcn) и $\left(\mathrm{Lu}_{1-x} \mathrm{Eu}_{x}\right)_{2}\left(\mathrm{MoO}_{4}\right)_{3}$ $0.5<x \leq 1$ (пр.гр. Рba2).

Как известно, максимально возможное число полос, соответствующих переходу ${ }^{5} \mathrm{D}_{0} \rightarrow{ }^{7} \mathrm{~F}_{2}(2 J+1)$ для $\mathrm{Re}^{3+}$-ионов, занимающих только одну позицию, равно 5. В то же время в спектре люминесценции $\left(\mathrm{Lu}_{1-x} \mathrm{Eu}_{x}\right)_{2}\left(\mathrm{MoO}_{4}\right)_{3}$ при $x>0.5$ в области длин волн 605-630 nm, как отмечалось выше, наблюдается семь полос (рис. 6). Такое количество линий возможно только в том случае, если $\mathrm{Eu}^{3+}$-ионы могут располагаться в двух неэквивалентных положениях. Эти результаты подтверждают данные рентгеноструктурных исследований, согласно которым в орторомбической $\beta^{\prime}$-фазе $\mathrm{Eu}_{2}\left(\mathrm{MoO}_{4}\right)_{3}$ (пр.гр. Pba2) для редкоземельного иона существует две позиции [17].

\section{2. Спектры возбуждения люминесценции}

Спектры возбуждения люминесценции наиболее интенсивных полос свечения молибдатов $\left(\mathrm{Lu}_{1-x} \mathrm{Eu}_{x}\right)_{2}\left(\mathrm{MoO}_{4}\right)_{3}$ представлены на рис. 7. Для всех этих соединений наиболее интенсивными являются три полосы: широкая коротковолновая полоса с переносом заряда (ППЗ), соответствующая электронному переходу с орбитали $2 p$ иона $\mathrm{O}^{2-}$ на орбиталь $4 f$ иона $\mathrm{Eu}^{3+}$, а также две узкие резонансные полосы, соответствующие переходам $\quad{ }^{7} \mathrm{~F}_{0} \rightarrow{ }^{5} \mathrm{~L}_{6} \quad$ и $\quad{ }^{7} \mathrm{~F}_{0} \rightarrow{ }^{5} \mathrm{D}_{2}$. Положения максимумов этих полос $\left(\lambda_{\max } \sim 280-282, \sim 394.5\right.$ и $\sim 465.5 \mathrm{~nm}$ соответственно) остаются неизменными при $0.01<x<0.5$ (рис. 7). При $x \geq 0.5$ происходит небольшой сдвиг максимумов ППЗ и резонансных полос в область бо́льших длин волн $-\lambda_{\max } \sim 288, \sim 395$ и $\sim 466 \mathrm{~nm}$ соответственно. При дальнейшем увеличении количества ионов $\mathrm{Eu}^{3+}$ вплоть до $x=1$ положения максимумов этих полос остаются неизменными.

Таким образом, в отличие от спектра люминесценции спектр возбуждения люминесценции $\left(\mathrm{Lu}_{1-x} \mathrm{Eu}_{x}\right)_{2}\left(\mathrm{MoO}_{4}\right)_{3}$ не изменяется при структурном переходе из моноклинной (пр.гр. $P 2_{1} / a$ ) в орторомбическую модификацию (пр.гр. $P b c n$ ), а переход в орторомбоческую структуру (пр.гр Pba2) сопровождается незначительными изменениями в СВЛ.

Зависимости интенсивности полос, имеющих максимальную интенсивность в спектре фотолюминесценции, от количества ионов европия $(x)$ при возбуждении соединений $\left(\mathrm{Lu}_{1-x} \mathrm{Eu}_{x}\right)_{2}\left(\mathrm{MoO}_{4}\right)_{3}$ светом с $\lambda=280-288 \mathrm{~nm}($ ППЗ) и 2395 и $\sim 466 \mathrm{~nm}$ (резонансные полосы) представлены на рис. 8, $a$. Как видно, 
Спектральные и структурные характеристики $\left(\mathrm{Lu}_{1-x} \mathrm{Eu}_{x}\right)_{2}\left(\mathrm{MoO}_{4}\right)_{3}$

\begin{tabular}{c|c|c|c|c|c}
\hline $\begin{array}{c}\text { Состав } \\
\left(\mathrm{Lu}_{1-x} \mathrm{Eu}_{x}\right)_{2}\left(\mathrm{MoO}_{4}\right)_{3}\end{array}$ & \multicolumn{3}{|c|}{$\begin{array}{c}\text { Основные максимумы полос } \\
\text { фотолюминесценции, } \mathrm{nm}\end{array}$} & Структура \\
\hline $0.01<x<0.2$ & 608.3 & 612.4 & & 616.6 & Моноклинная $\left(\right.$ пр. гр. $\left.P 2_{1} / a\right)$ \\
\hline $0.2<x<0.4$ & 608.3 & 612.4 & & & Орторомбическая (пр. гр. $P b c n)$ \\
\hline$x=0.5$ & 608.3 & 612.4 & 614.4 & 616.6 & $\begin{array}{c}\text { Орторомбическая (пр. гр. } P b c n) \\
\text { и Орторомбическая (пр. гр. } P b a 2)\end{array}$ \\
\hline $0.5<x \leq 1$ & & & 614.4 & 616.6 & Орторомбическая (пр. гр. Pba2)
\end{tabular}

изменения интенсивности полос в зависимости от доли европия изменяются немонотонно. Это связано с тем, что при увеличении количества европия в соединении $\left(\mathrm{Lu}_{1-x} \mathrm{Eu}_{x}\right)_{2}\left(\mathrm{MoO}_{4}\right)_{3}$ изменяется его структура и происходит увеличение доли фазы $\left(\mathrm{Lu}_{0.2} \mathrm{Eu}_{0.8}\right)_{2}\left(\mathrm{MoO}_{4}\right)_{3}$. Максимальная величина наиболее интенсивной полосы в спектре люминесценции $\left(\mathrm{Lu}_{1-x} \mathrm{Eu}_{x}\right)_{2}\left(\mathrm{MoO}_{4}\right)_{3}$ при возбуждении в полосе с переносом заряда наблюдается при

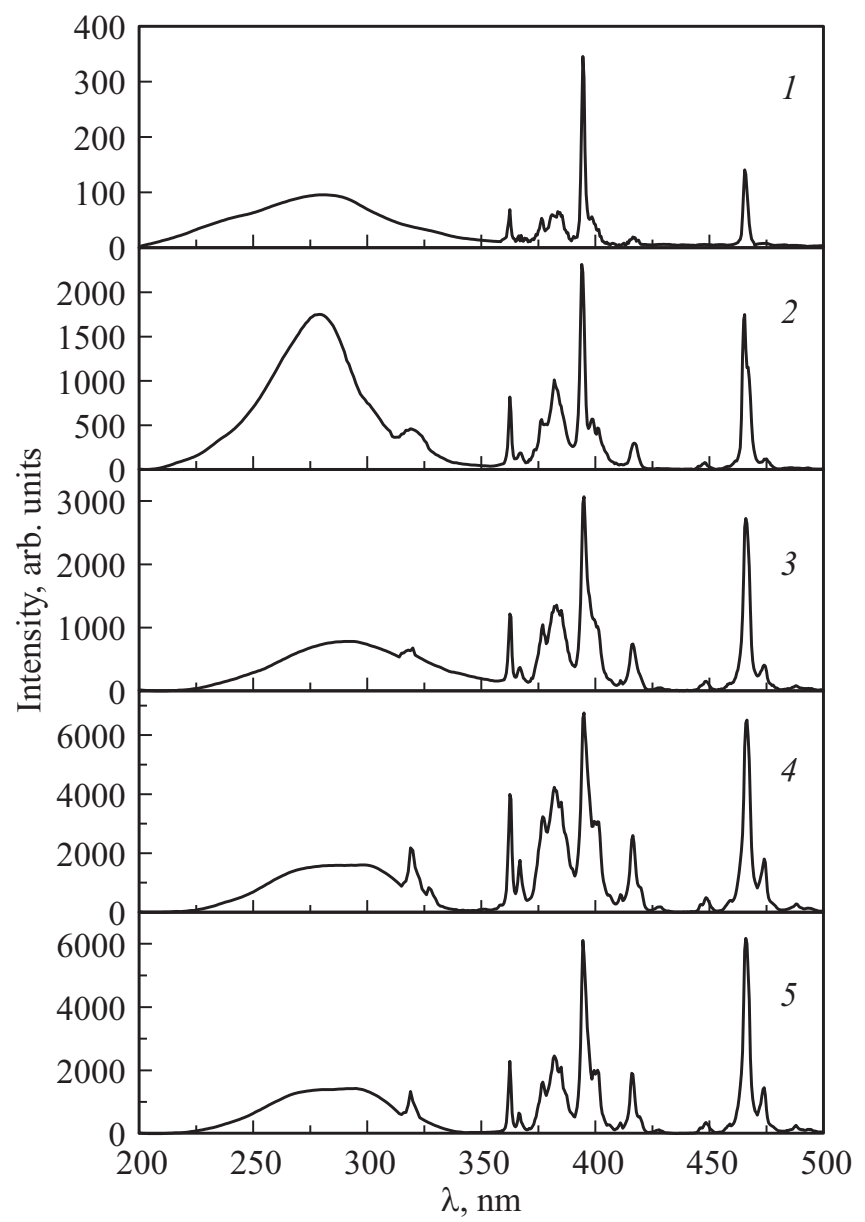

Рис. 7. Спектры возбуждения люминесценции молибдатов $\left(\mathrm{Lu}_{1-x} \mathrm{Eu}_{x}\right)_{2}\left(\mathrm{MoO}_{4}\right)_{3} . \quad 1-\left(\mathrm{Lu}_{0.99} \mathrm{Eu}_{0.01}\right)_{2}\left(\mathrm{MoO}_{4}\right)_{3}$; $2-\left(\mathrm{Lu}_{0.8} \mathrm{Eu}_{0.2}\right)_{2}\left(\mathrm{MoO}_{4}\right)_{3} ; 3-\left(\mathrm{Lu}_{0.5} \mathrm{Eu}_{0.5}\right)_{2}\left(\mathrm{MoO}_{4}\right)_{3} ; 4-$ $\left(\mathrm{Lu}_{0.2} \mathrm{Eu}_{0.8}\right)_{2}\left(\mathrm{MoO}_{4}\right)_{3} ; 5-\mathrm{Eu}_{2}\left(\mathrm{MoO}_{4}\right)_{3} ; 1,2-$ максимум свечения $\lambda_{\max }=612.4 \mathrm{~nm} ; 3,4,5-\lambda_{\max }=614.4 \mathrm{~nm}$.

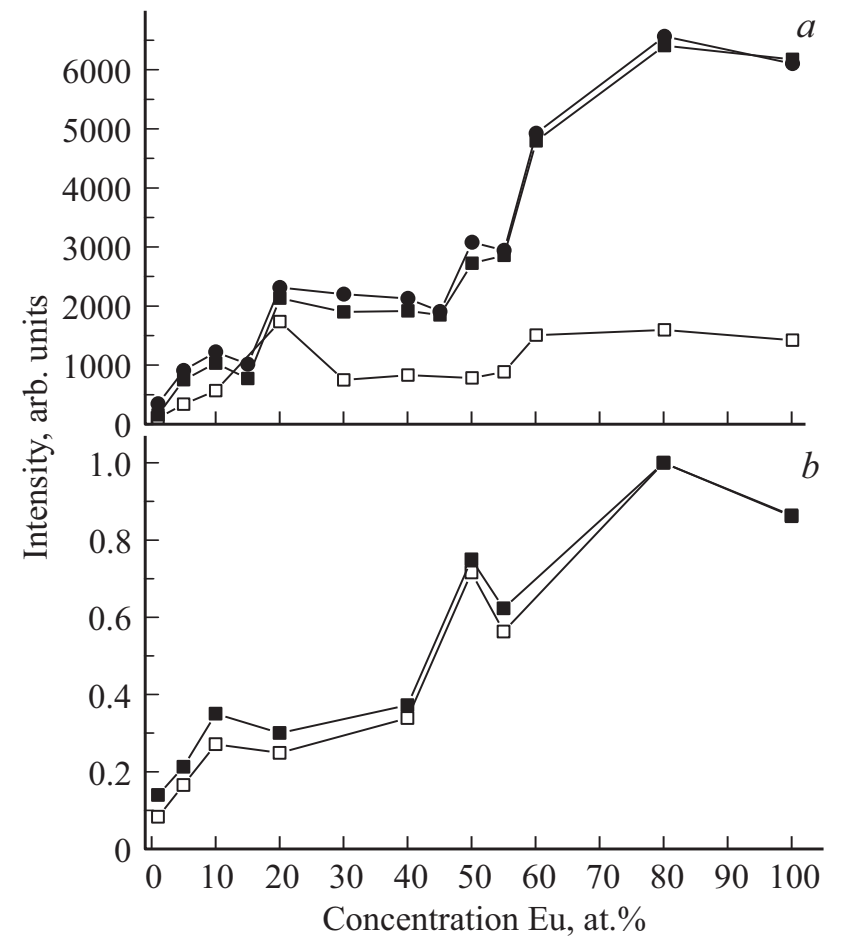

Рис. 8. Зависимости свечения молибдатов $\left(\mathrm{Lu}_{1-x} \mathrm{Eu}_{x}\right)_{2}\left(\mathrm{MoO}_{4}\right)_{3}$ от концентрации ионов $\mathrm{Eu}^{3+}$. a) Зависимости имеющих максимальную интенсивность полос свечения при возбуждении светом: $\square-\lambda_{\mathrm{ex}}=$ ППЗ; $\bullet-$ $\lambda_{\mathrm{ex}}=395 \mathrm{~nm}$; - $\lambda_{\mathrm{ex}}=466 \mathrm{~nm} ;$ при $0.01 \leq x \leq 0.4$ максимум свечения $\lambda_{\max }=612.4 \mathrm{~nm}$; при $0.5<x \leq 1-\lambda_{\max }=614.4 \mathrm{~nm}$; $b)$ Площади под кривыми люминесценции в диапазонах: $(-$ - ) 605-630 и (-口-) 570-720 nm.

$x=0.2$. При возбуждении светом, соответствующим резонансным полосам поглощения с $\lambda_{\max }=395$ и $466 \mathrm{~nm}$, максимальная интенсивность свечения наблюдается при $x=0.8$ (рис. $8, a)$.

На рис. $8, b$ приведены зависимости интегральной интенсивности свечения образцов $\left(\mathrm{Lu}_{1-x} \mathrm{Eu}_{x}\right)_{2}\left(\mathrm{MoO}_{4}\right)_{3}-$ площади под кривыми люминесценции в диапазонах 605-630 и 570-720 nm (рис. 5 и 6 соответственно) от содержания ионов европия. Характер этих зависимостей одинаков, однако интеграл в широком диапазоне спектра на $\sim 25 \%$ выше, чем в более узком. Следует 
заметить, что эти зависимости идентичны зависимостям интенсивности свечения $\left(\mathrm{Lu}_{1-x} \mathrm{Eu}_{x}\right)_{2}\left(\mathrm{MoO}_{4}\right)_{3}$ от содержания ионов европия при резонансном возбуждении $\mathrm{Eu}^{3+}$ (рис. 8,a), но более полно отражают изменение светимости образца в зависимости от содержания ионов европия.

Как известно, электронные переходы между состояниями свободных $\mathrm{Eu}^{3+}$-ионов, принадлежащих одной, в нашем случае $4 f^{n}$-конфигурации, запрещены по четности $[27,28]$. Под действием кристаллического поля этот запрет частично снимается. При замещении имеющих большой ионный радиус ионов $\mathrm{Eu}^{3+}$ ионами $\mathrm{Lu}^{3+}$, имеющих значительно меньший ионный радиус, величина кристаллического поля вокруг $\mathrm{Eu}^{3+}$ возрастает, что приводит к еще большему снятию запрета и увеличению интенсивности свечения европия вплоть до предела растворимости лютеция в $\mathrm{Eu}_{2}\left(\mathrm{MoO}_{4}\right)_{3}$. Поэтому максимум свечения $\mathrm{Eu}^{3+}$ наблюдается для соединения $\left(\mathrm{Lu}_{0.2} \mathrm{Eu}_{0.8}\right)_{2}\left(\mathrm{MoO}_{4}\right)_{3}$. При увеличении количества европия в соединении $\mathrm{Lu}_{2}\left(\mathrm{MoO}_{4}\right)_{3}$ из-за различия ионных радиусов европия и лютеция также возникают искажения кристаллической решетки, которые приводят к увеличению кристаллического поля в образце. Однако соединения $\left(\mathrm{Lu}_{1-x} \mathrm{Eu}_{x}\right)_{2}\left(\mathrm{MoO}_{4}\right)_{3}$ при увеличении количества европия образуют, как отмечалось, вначале моноклинную $P 2_{1} / a$, а затем орторомбическую фазы, $P b c n$. Эти структуры имеют плотность на $\sim 12 \%$ меньше, чем структура $\mathrm{Eu}_{2}\left(\mathrm{MoO}_{4}\right)_{3}, \mathrm{Pba2}$. Поэтому изменение кристаллического поля в этих структурах не столь велико, как в структурном типе 2. Кроме того, доля европия в структурном типе 1 меньше. Поэтому максимальная интенсивность свечения наблюдается при максимуме растворимости лютеция в $\mathrm{Eu}_{2}\left(\mathrm{MoO}_{4}\right)_{3}$.

Следует отметить, что при рентгенофазовом анализе образцов мы получаем информацию о структуре образца, усредненную по его объему, определяемому глубиной проникновения рентгеновского излучения, которая составляет в наших экспериментах $\sim 10 \mu \mathrm{m}$. Это сравнимо со средним размером исследуемых микрокристаллов (рис. 1), поэтому при рентгенофазовом анализе мы получаем информацию о структуре всего образца. В то же время структуры на поверхности и в объеме образца могут существенно отличаться $[11,29]$.

Как известно, $\mathrm{RE}^{3+}$-ионы чувствительны к ближайшему окружению $[27,28]$. Поэтому по изменению спектральных характеристик $\mathrm{RE}^{3+}$-ионов можно судить об изменении их локального окружения даже тогда, когда дальний порядок (определенная структурная модификация) отсутствует.

В работах $[9,11,27]$ показано, что если ближний порядок вокруг $\mathrm{Eu}^{3+}$-ионов во всем образце одинаков, о чем свидетельствует совпадение спектров люминесценции приповерхностного слоя образца и его объема, то весь образец структурно однороден. Информацию о ближайшем окружении $\mathrm{RE}^{3+}$-ионов в объеме образца можно получить, возбуждая люминесценцию редкоземельных ионов светом с энергией, соответствующей резонансному возбуждению $\mathrm{RE}^{3+}$-ионов, но в области прозрачности образца. Возбуждение свечения редкоземельных ионов светом с энергией, находящейся в области интенсивного поглощения образца (либо зоназонного поглощения, либо в области полосы с переносом заряда), позволяет получить информацию о локальном окружении $\mathrm{RE}^{3+}$-ионов в приповерхностном слое образца. Для исследованных в настоящей работе образцов полоса с переносом заряда (рис. 7) находится при $\lambda=282-288 \mathrm{~nm}$. Резонансные полосы с $\lambda_{\max } \sim 395$ и $\sim 466 \mathrm{~nm}$ расположены в области прозрачности образцов, как $\mathrm{Lu}_{2}\left(\mathrm{MoO}_{4}\right)_{3}$, так и $\mathrm{Eu}_{2}\left(\mathrm{MoO}_{4}\right)_{3}$. Поэтому при возбуждении свечения образца светом с $\lambda=282-288$ и $\sim 395 \mathrm{~nm}$ мы получаем информацию о ближайшем окружении $\mathrm{RE}^{3+}$-ионов в приповерхностном слое и в объеме образца соответственно.

Как уже отмечалось, спектры люминесценции (СЛ) образцов $\left(\mathrm{Lu}_{1-x} \mathrm{Eu}_{x}\right)_{2}\left(\mathrm{MoO}_{4}\right)_{3}$ не зависят от длины волны возбуждающего света - СЛ при возбуждении приповерхностного слоя образца $\left(\lambda_{\mathrm{ex}}=282-288 \mathrm{~nm}\right)$ и его объема $\left(\lambda_{\mathrm{ex}} \sim 395 \mathrm{~nm}\right)$ совпадают (рис. 6, спектр 3), поэтому ближайшее окружение $\mathrm{Eu}^{3+}$-ионов в этих образцах остается неизменным во всем объеме образца. Это свидетельствует о том, что исследованные соединения структурно однородны.

\section{7. Заключение}

1. Установлено однозначное соответствие между структурной модификацией и спектральными характеристиками фотолюминесценции и ИК-поглощенияения молибдатов $\left(\mathrm{Lu}_{1-x} \mathrm{Eu}_{x}\right)_{2}\left(\mathrm{MoO}_{4}\right)_{3}(0 \leq x \leq 1)$.

2. Увеличение концентрации европия приводит к последовательному изменению структурного состояния и спектральных характеристик молибдатов:

- при $0 \leq x<0.2$ образцы имеют моноклинную структуру (пр.гр. № 14, $\left.P 2_{1} / a\right)$ и соответствующий этой структуре спектр фотолюминесценции содержит 3 полосы с $\lambda_{\max } \sim 608.3, \sim 612.4$ и $\sim 616.6 \mathrm{~nm}$;

- при $0.2 \leq x<0.4$ реализуется орторомбическая структура (пр.гр. № 60, Pbcn), и в спектре свечения наблюдаются только две полосы с $\lambda_{\max } \sim 608.3$ и $612.4 \mathrm{~nm}$;

- при $0.8<x \leq 1$ образцы имеют орторомбическую структуру (пр. гр. № 32, Pba2) и соответствующий этой структуре спектр фотолюминесценции содержит ряд новых полос, среди которых наибольшую интенсивность имеют полосы с $\lambda_{\max } \sim 614.4$ и $\sim 616.6 \mathrm{~nm}$;

- при $0.4<x<0.8$ образцы содержат орторомбические фазы Pbcn и Pba2, а спектры люминесценции $\left(\mathrm{Lu}_{1-x} \mathrm{Eu}_{x}\right)_{2}\left(\mathrm{MoO}_{4}\right)_{3}$ и ИК-поглощенияения являются суперпозицией спектров этих двух фаз.

3. Впервые исследованы спектры фотолюминесценции и ИК-поглощенияения моноклинной структуры $P 2_{1} / a$ (пр. гр. № 14) соединений $\left(\mathrm{Lu}_{1-x} \mathrm{Eu}_{x}\right)_{2}\left(\mathrm{MoO}_{4}\right)_{3}$.

4. Показано, что максимальная интенсивность свечения ионов $\mathrm{Eu}^{3+}$ при возбуждении светом, со- 
ответствующим резонансным полосам поглощения $\left(\lambda_{\mathrm{ex}}=395\right.$ и $\left.466 \mathrm{~nm}\right)$, наблюдается для соединения $\left(\mathrm{Lu}_{0.2} \mathrm{Eu}_{0.8}\right)_{2}\left(\mathrm{MoO}_{4}\right)_{3}$. Это соединение имеет высокую интенсивность свечения и может быть использовано в качестве эффективного красного люминофора для светодиодных источников света.

Авторы выражают благодарность ЦКП НО ИФТТ РАН за исследование морфологии образцов и их характеризацию методом ИК-спектроскопии Н.Ф. Прокопюку за помощь в проведении экспериментов.

\section{Список литературы}

[1] M.J. Weber, S.E. Derenso, C. Dujardin. Proceedings of SCINT 95 / Eds. P. Dorenbos, C.W.E. van Eijk. Delft, TheNetherlands (1996). P. 325.

[2] N.V. Klassen, S.Z. Shmurak, I.M. Shmyt'ko, G.K. Strukova, S.E. Derenso, M.J. Weber. Nucl. Instrum. Meth. Phys. Res. A 537, 144 (2005).

[3] V.V. Mikhailin, D.A. Spassky, V.N. Kolobanov, A.A. Meatishvily, D.G. Permenov, B.I. Zadneprovski. Rad. Measurements 45, 307 (2010).

[4] J. Yang, C. Li, X. Zhang, Z. Quan, C. Zhang, H. Li, J. Lin. Chem. Eur. J. 14, 4336 (2008).

[5] J. Hälsö. Inorg. Chim. Acta 139, 257 (1987).

[6] С.3. Шмурак, В.В. Кедров, А.П. Киселев, И.М. Шмытько. ФTT 57, 19 (2015).

[7] С.З. Шмурак, В.В. Кедров, А.П. Киселев, Т.Н. Фурсова, И.М. Шмытько. ФТТ 57, 1558 (2015).

[8] Y.H. Zhou, J. Lin, S.B. Wang, H.J. Zhang. Opt. Mater. 20, 13 (2002).

[9] С.3. Шмурак, А.П. Киселев, В.В. Синицын, И.М. Шмытько, А.С. Аронин, Б.С. Редькин, Е.Г. Понятовский. ФТТ 48, 48 (2006).

[10] S.Z. Shmurak, A.P. Kiselev, N.V. Klassen, V.V. Sinitsyn, I.M. Shmyt'ko, B.S. Red'kin, S.S. Khasanov. IEEE Trans. Nucl. Sci. 55, 1128 (2008).

[11] С.3. Шмурак, А.П. Киселев, Д.М. Курмашева, Б.С. Редькин, В.В. Синицын. ЖЭТФ 137, 867 (2010).

[12] E.M. Levin, R.S. Roth, J.B. Martin. Am. Miner. 46, 1030 (1961).

[13] L.N. Brixner, J.R. Barkley, W. Jeitschko. In: Handbook on the Physics and Chemistry of Rare Earth / Ed. by K.A. Gschneidner, Jr.L. Eyring. North-Holland Publishing Company (1979). P. 609.

[14] Bo Wang, Xiaoshuang Li, Qingguang Zeng, GuotaoYang, Jianyi Luo, Xin He, Yeqing Chen. Mater. Res. Bul. 100, 97 (2018).

[15] Н.С. Ахметов. Неорганическая химия. Высш. шк. М. (1975). C. 548.

[16] Horng-yih Chen. Mater. Res. Bull. 14, 1583-1590, (1979).

[17] E.T. Keve, S.C. Abrachams, J.L. Bernstein. J. Chem. Phys. 54, 3185 (1971).

[18] S. Sheik Saleem, G. Aruldhas, H.D. Bist. Spectrochim. Acta 39A, 1049 (1983).

[19] S. Sheik Saleem, G. Aruldhas, H.D. Bist. J. Solid State Chem. 48, 77 (1983)

[20] J. Petzelt, V. Dvořák. Phys. Status Solidi (b) 46, 413 (1973).

[21] M. del C. Viola, A.M. Sangra, J.C. Pedregosa. J. Mater. Sci. 28, 6587 (1993).
[22] S. Sheik Saleem, T.K.K. Srinivasan. Spectrochim. Acta 41A, 1419 (1985).

[23] А.В. Баженов, Т.Н. Фурсова, А.П. Киселев, С.3. Шмурак, С.С. Хасанов. ФТТ 53, 760 (2011).

[24] Shiliang Zhou, Gözde Barim, Benjamin J. Morgan, Brent C. Melot, Richard L. Brutchey. Chem. Mater. 28, 4492 (2016).

[25] C. Mansuy, J.M. Nedelec, C. Dujardin, R. Mahiou. Opt. Mater. 29, 697 (2007).

[26] V.A. Efremov, B.I. Lazoryak, V.K. Trunov. Kristallografiya 26, 72 (1981).

[27] М.А. Ельяшевич. Спектроскопия редких земель. ГИТТЛ, M. (1953). $456 \mathrm{c.}$

[28] М.И. Гайдук, В.Ф. Золин, Л.С. Гайгерова. Спектры люминесценции европия. Наука, М. (1974). 195 с.

[29] А.П. Киселев, С.З. Шмурак, Б.С. Редькин, В.В. Синицын, И.М. Шмытько, Е.А. Кудренко, Е.Г. Понятовский. ФТТ 48, 1458 (2006).

Редактор Ю.Э. Китаев 